\title{
Moderate to Severe Osteoarthritis Pain and Its Impact on Patients in the United States: A National Survey
}

\author{
Patricia Schepman (1) \\ Sheena Thakkar (D) \\ Rebecca Robinson (iD) ${ }^{2}$ \\ Deepa Malhotra' \\ Birol Emir ${ }^{\prime}$ \\ Craig Beck' \\ 'Pfizer Inc., New York, NY, USA; ' ${ }^{2}$ Eli Lilly \\ and Company, New York, NY, USA
}

Correspondence: Sheena Thakkar Pfizer Inc., 235 East 42nd Street, New York, NY, 10017, USA

Tel + I 347 96I-9174

Email sheena.thakkar@pfizer.com
Purpose: Osteoarthritis (OA) is one of the most common causes of chronic pain and a leading cause of disability in the US. The objective of this study was to examine the clinical and economic burden of OA by pain severity.

Patients and Methods: We used nationally representative survey data. Adults $\geq 18$ years with self-reported physician-diagnosed OA and experiencing OA pain were included in the study. OA pain severity was measured using the Short Form McGill Pain Questionnaire Visual Analog Scale (SF-MPQ-VAS). Data were collected for demographics, clinical characteristics, healthrelated quality of life (HRQoL), productivity, OA treatment, adherence to pain medication, and healthcare resource utilization. Univariate analysis was performed to examine differences between respondents with moderate-to-severe OA pain vs those with mild OA pain.

Results: Higher proportions of respondents with moderate-to-severe OA pain $(n=3798)$ compared with mild OA pain $(n=2038)$ were female $(69.4 \%$ vs $57.3 \%),<65$ years of age (54.8\% vs $43.4 \%$ ), and not employed (70.6\% vs $64.5 \%)$. Respondents with moderate-tosevere OA pain experienced OA pain daily ( $80.8 \%$ vs $48.8 \%$ ), were obese $(53.0 \%$ vs $40.5 \%)$, had more comorbidities (sleep disturbance, insomnia, depression, and anxiety), and reported significantly poorer health status and HRQoL, and greater productivity and activity impairment (all $P<0.05$ ). Moderate-to-severe OA pain respondents were prescribed significantly more pain medications than mild OA pain respondents $(41.0 \%$ vs $17.0 \%)$ and had higher adherence (75.9\% vs $64.1 \%$ ) yet were less satisfied with their pain medications (all $P<0.001)$. Outpatient and emergency room visits, and hospitalizations in the 6 months prior to the survey were significantly higher in moderate-to-severe OA pain respondents vs those with mild OA pain (all $P<0.05$ ).

Conclusion: Patient and clinical burden was significantly greater in moderate-to-severe OA pain respondents vs mild OA pain respondents and may inform decision-making for appropriate resource allocation and effective management strategies that target specific subgroups. Keywords: osteoarthritis, moderate-to-severe pain, pain severity, health-related quality of life, HRQoL, healthcare resource utilization, HCRU, medication adherence, treatment satisfaction

\section{Introduction}

Chronic pain impacts approximately 100 million individuals in the United States (US), accounting for an estimated $\$ 560$ to $\$ 635$ billion per year (2010 dollars) in direct and indirect healthcare costs, including lost workplace productivity. ${ }^{1}$ Osteoarthritis (OA) is one of the most common causes of chronic pain and a leading cause of disability in the $\mathrm{US}^{2-4}$ impacting activities of daily living. ${ }^{5} \mathrm{OA}$, the most common form of arthritis, is 
a joint disorder characterized by swelling, stiffness, inflammation, and pain that negatively impacts both physical and mental health in more than 32.5 million adults in the US. ${ }^{4,6-9}$ $\mathrm{OA}$ is associated with substantial economic and societal burdens resulting from functional impairment, decreased health-related quality of life (HRQoL), increased healthcare resource utilization (HCRU) and costs. ${ }^{8,10-19}$

Given the heterogeneity of patients with OA, development of new therapies to treat $\mathrm{OA}$ pain often requires targeting patient subgroups such as those with different levels of pain severity. For example, therapies targeting moderate-to-severe OA pain require a thorough understanding of the burden of illness and unmet need in this population. Establishing a new treatment's positioning among available treatment options for OA will be critical to the population it serves and will provide value to payers and healthcare providers.

The humanistic and economic burden of OA has been investigated, to some extent, by disease and pain severity levels. ${ }^{19-25}$ Of 7 publications representing 6 unique studies, one study examined OA patients using claims and electronic health record (EHR) data, ${ }^{22}$ and the remaining studies were based on patient and/or healthcare provider surveys. Two of the 6 studies focused on disease or OA severity, ${ }^{20,21}$ and 4 stratified OA patients by pain severity ${ }^{19,22-25}$ even though two studies did not specify the pain as OA-specific. ${ }^{19,22}$

In those studies, pain severity was assessed using several measures including:

- Numeric rating scales (NRS)

○ NRS; generic 0-10

- Western Ontario and McMaster Universities Arthritis Index or WOMAC $3.1^{26}$

- Visual analog scales (VAS)

○ VAS; generic 0-100

○ Short-Form McGill Pain Questionnaire VAS (SFMPQ-VAS) ${ }^{27,28}$

- Likert scale

- Pain Interference with Activities (PIA) scale derived from the 12-item Short Form Health Survey (SF-12v2) developed for the Medical Outcomes Study. ${ }^{29}$

While all of these measures are well-accepted, ${ }^{30}$ the recall periods in the studies varied from 48 hours to 7 days to 4 weeks. When specified, cut points for pain severity were generally similar: 0-3 representing no/mild, 4-6 for moderate, 7-10 for severe, and 4-10 for moderate-to-severe pain.
All of the published studies compared cohorts of no/ mild pain with increasing severity cohorts. Four of the 6 studies examined differences between no/mild, moderate, and severe patients ( 1 study vs a non-OA cohort), ${ }^{20-22,24,25}$ and 2 compared no/mild vs moderate-to-severe pain. ${ }^{19,23}$ For most outcomes examined, increasing burden was observed with increasing OA and/or pain severity.

None of the studies exclusively investigated the burden of patients with symptomatic OA pain in a nationally representative sample that included treated and nontreated patients. This study provides a comprehensive, holistic view of the clinical and economic burden of OA by pain severity, in symptomatic patients only, from the patient perspective using a geographically representative national sample in a real-world setting. Clinical and economic burdens were examined in patients with moderate-tosevere OA pain vs mild OA pain, with a focus on patient demographics, comorbidities, HRQoL, pain medication use (including satisfaction and adherence), and HCRU.

\section{Patients and Methods Data Source and Population}

Data were from the OA-specific module of the Kantar 2019 (January through December) US National Health and Wellness Survey (NHWS), a cross-sectional, nationally representative observational survey of general health. ${ }^{31}$ Respondents were identified primarily through opt-in online survey panels, with stratified random sampling within the panel to ensure representativeness for age and gender. Adults $\geq 18$ years with self-reported physiciandiagnosed $\mathrm{OA}$ and experiencing OA pain were included in the study. Respondents were excluded if they reported cancer pain, no OA pain, or that the only joint affected by OA was the back, shoulder, or neck.

Patients were stratified into OA pain severity cohorts based on responses to the SF-MPQ-VAS that assesses pain severity over the past week. ${ }^{28,32}$ Severity strata were based on scores of 1-34 for mild pain, 35-74 for moderate pain, and $\geq 75$ for severe pain. Patients with scores of 0 (no OA pain) were excluded, and the moderate-to-severe cohort consisted of the combination of those with moderate and severe pain scores.

\section{Outcomes}

Demographic and Clinical Characteristics

All outcomes were self-reported including patient demographics (age, gender, race/ethnicity, employment status, 
and income level) and clinical characteristics of $\mathrm{OA}$ (affected joint or body region; duration of OA in years; frequency of OA pain in days, weeks, and months). Other clinical characteristics collected were comorbidities including sleep difficulties, depression and anxiety, and the Charlson Comorbidity Index (CCI). ${ }^{33}$ Information on body mass index (BMI), exercise, alcohol use, and smoking status was also captured and stratified by OA pain severity.

\section{Health-Related Quality of Life (HRQoL)}

HRQoL was measured using several validated instruments. Domains of HRQoL were evaluated using the Medical Outcomes Study (MOS) 36-item Short Form version 2 (SF-36v2) consisting of 36 items that assess general health and wellbeing over the past 4 weeks and includes 8 domain scores: physical functioning, role physical, bodily pain, general health, vitality, social function, role emotional, and mental health. ${ }^{34}$ Two summary scores, the mental component summary (MCS) and physical component summary (PCS), were also calculated. Scores range from 0 to 100 with higher scores indicating better HRQoL. The Short Form 6-dimension (SF-6D) health state utility score was calculated from the SF-36v2. ${ }^{35}$

The 5-level EQ-5D version (EQ-5D-5L) was used to assess general health status. The EQ-5D-5L consists of 5 questions that encompass mobility, self-care, usual activities, pain/discomfort, and anxiety/depression. ${ }^{36-38}$ Each dimension has 5 scoring levels (no problems, slight problems, moderate problems, severe problems, and extreme problems) that enable calculation of health state utilities, which range from 0 (death) to 1 (perfect health).

\section{Work Productivity}

Work productivity was assessed using the validated 6-item Work Productivity and Activity Impairment General Health V2.0 questionnaire (WPAI-GH), which has a 7-day recall period. The WPAI-GH includes 4 subscales: absenteeism (absence from work), presenteeism (lost productivity while at work), overall work impairment (based on absenteeism and presenteeism), and overall activity impairment. All subscales are scored from $0 \%$ to $100 \%$, with higher scores indicative of greater work or activity impairment. ${ }^{39,40}$ While the regular activities subscale was evaluated in all respondents, the work productivity subscales were evaluated only among employed respondents.

\section{Medication Use for OA Pain}

Current use of over the counter (OTC) pain medications to treat respondents' OA pain was captured for ibuprofen, acetaminophen, naproxen, and acetylsalicylic acid. Information on the type of OA pain medication prescribed and the number of pain medications received was collected. Prescription medication duration was measured as the length of time, in months, that respondents reported using pain medication, and medication frequency was assessed as the maximum number of days any prescription pain medication was taken during the previous month. Medication adherence was assessed using the simple version of the Medication Adherence Rating Scale (MARS), ${ }^{41}$ for which respondents provided an estimate of how much, as a percentage, of their prescribed pain medication they had taken in the last 4 weeks. Respondents' satisfaction with their current medication was measured using the stand-alone question "How satisfied are you with these prescription medication(s)?", using a Likert scale of 1-7 ( $1=$ extremely dissatisfied, $7=$ extremely satisfied).

\section{Healthcare Resource Utilization (HCRU)}

Respondents were asked about their use of aids for OA including cold compresses, heat packs/patches, knee wraps, medical devices (eg, transcutaneous electrical nerve stimulation [TENS]), and braces. Respondents were also asked about their HCRU in the 6 months prior to the survey for categories of any outpatient visits, OArelated emergency room or urgent care visits, and $\mathrm{OA}$ related hospitalizations.

\section{Statistical Analyses}

Total population and cohorts were analyzed using descriptive statistics; categorical variables were summarized as counts and proportions of the total study population and by subgroups as appropriate, and continuous variables were summarized as means and standard deviations. To represent the demographic composition of the US population, the data were weighted by gender, age and race/ethnicity. ${ }^{31}$ For pairwise comparisons of categorical variables, first-order RaoScott chi-square tests were employed. For mean differences between continuous variables, $t$-tests were used. Statistical significance was defined as $P<0.05$. All analyses were performed using Statistical Analysis System (SAS) version 9.4 or higher (SAS Institute, Cary, NC, USA). 


\section{Results}

Among 74,994 NHWS participants in 2019, 8607 (11.5\%) self-reported a physician diagnosis of OA, of whom 5836 reported experiencing OA pain and were included in the analysis (Figure 1). These respondents were stratified into cohorts of mild $(\mathrm{n}=2038)$ and moderate-to-severe $(\mathrm{n}=3798)$ OA pain. Mean SF-MPQ-VAS was 19.7 (range 1-34) for mild OA pain respondents and 60.0 (range 35100) for moderate-to-severe OA pain respondents.

Significant differences were observed between the two OA pain cohorts with respect to gender, age, race and ethnicity, and employment $(P<0.0001)$ (Table 1$)$. The moderate-to-severe cohort was younger (61.9 vs 64.3 years), had higher proportions of females $(69.4 \%$ vs $57.3 \%)$, nonHispanic Blacks (7.9\% vs $4.0 \%)$, and Hispanics $(4.0 \%$ vs $2.8 \%$ ) compared to the mild OA pain cohort. More moderate-to-severe OA pain respondents were of working age ( $<65$ years old), yet fewer were employed $(29.5 \%$ vs $35.5 \%$ ), and a greater proportion were on long-term disability leave (12.4\% vs $3.8 \%$ ) compared to mild OA pain respondents. Fewer moderate-to-severe respondents reported an income $\geq \$ 75,000$ compared with mild OA pain $(26.4 \%$ vs $42.1 \%)$.

Statistically significant differences were observed between cohorts with respect to comorbidities, weight, and lifestyle preferences $(P<0.0001)$ (Table 2$)$. Mean CCI $(0.68$ vs 0.45 ) and CCI scores $>1$ were reported in a higher proportion of those with moderate-to-severe $\mathrm{OA}$ pain relative to mild (37.8\% vs $23.9 \%$ ), and these respondents also had a higher self-reported diagnosis of sleep disturbance ( $16.4 \%$ vs $7.8 \%$ ), insomnia ( $25.3 \%$ vs $12.2 \%$ ), depression (41.6\% vs $23.6 \%)$, and general anxiety disorder $(19.1 \%$ vs $10.2 \%$ ) compared with mild OA pain. As indicated by the BMI, obesity was more prevalent among those with moderate-to-severe OA pain, and a higher proportion of these respondents also reported not having exercised for at least 20 minutes in the past month (53.5\% vs $36.6 \%)(P<0.0001)$. Smoking status was significantly different between severity levels $(P<0.0001)$; a higher proportion of respondents with moderate-to-severe OA pain reported a history of smoking (current or former) relative to respondents with mild OA pain $(54.0 \%$ vs $48.6 \%)$.

Significant differences were also observed for OA type, length of OA, and OA pain frequency $(P<0.01)$ (Table 3 ). Higher proportions of patients with moderate-to-severe OA pain had OA of the knee, finger, hip, spine, hand, shoulder, and neck, although these categories were not mutually exclusive. The majority of OA pain patients had more than 1 joint affected, with higher proportions in the moderate-tosevere cohort ( $89.5 \%$ vs $79.2 \%$ ), including mean number of joints affected (4.8 vs 3.4) compared with mild OA. Significantly more patients with moderate-to-severe OA pain reported their arthritis as a result of injury compared with mild OA pain ( $36.1 \%$ vs $31.6 \%$ ). Among these patients, median age of moderate-to-severe $\mathrm{OA}$ respondents was younger than those with mild OA pain (60.6 vs 62.0 years)

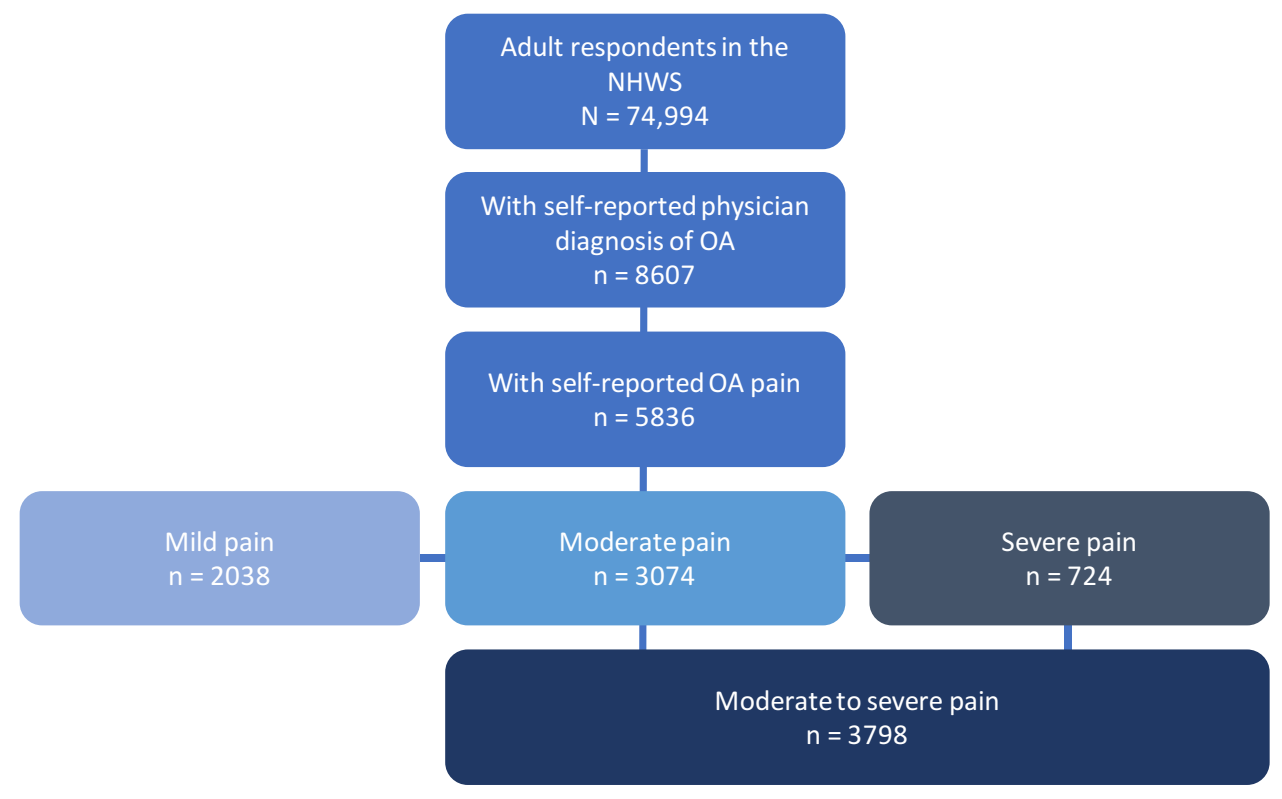

Figure I Study population attrition.

Abbreviations: NHWS, National Health and Wellness Survey; OA, osteoarthritis. 
Table I Demographic Characteristics

\begin{tabular}{|c|c|c|}
\hline \multirow[t]{2}{*}{ Variable } & \multicolumn{2}{|c|}{ Number of Patients (Weighted \%) } \\
\hline & Mild OA Pain $(n=2038)$ & Moderate-to-Severe OA Pain $(n=3798)$ \\
\hline Female* & $1259(57.3)$ & $2832(69.4)$ \\
\hline \multicolumn{3}{|l|}{ Age (years) } \\
\hline $18-34$ & $39(2.1)$ & 71 (I.8) \\
\hline $35-44$ & $86(4.4)$ & $210(5.5)$ \\
\hline $45-54 *$ & $187(10.7)$ & $539(16.2)$ \\
\hline $55-64 *$ & $585(26.2)$ & $1365(31.3)$ \\
\hline$\geq 65$ & II4I (56.6) & $1613(45.2)$ \\
\hline \multicolumn{3}{|l|}{ Race/ethnicity } \\
\hline Non-Hispanic White* & $1766(86.6)$ & $3116(82.3)$ \\
\hline Non-Hispanic Black* & $82(4.0)$ & $300(7.9)$ \\
\hline Hispanic $^{\dagger \dagger}$ & $55(2.8)$ & $|6|(4.0)$ \\
\hline Other & $135(6.6)$ & $221(5.8)$ \\
\hline \multicolumn{3}{|l|}{ Income (\$) } \\
\hline$<25,000^{*}$ & $25 \mid(\mid 2.2)$ & $901(23.6)$ \\
\hline $25,000-49,999^{\dagger}$ & $463(23.1)$ & $1026(26.6)$ \\
\hline $50,000-74,999$ & $367(17.7)$ & $74 \mid(19.6)$ \\
\hline$\geq 75,000 *$ & $858(42.1)$ & $1007(26.4)$ \\
\hline Missing/unknown & $99(5.0)$ & $123(3.9)$ \\
\hline \multicolumn{3}{|l|}{ Employment status } \\
\hline Employed* & $720(35.5)$ & II 57 (29.5) \\
\hline Full-time* & $425(21.0)$ & $644(16.6)$ \\
\hline Part-time & $169(8.1)$ & $274(6.7)$ \\
\hline Self-employed & $126(6.5)$ & $239(6.2)$ \\
\hline Not employed* & $1318(64.5)$ & $264 I(70.6)$ \\
\hline Retired $^{\dagger}$ & $1057(52.4)$ & $1677(47.0)$ \\
\hline Student & $8(0.4)$ & $17(0.5)$ \\
\hline Long-term disability* & $83(3.8)$ & $502(12.4)$ \\
\hline Looking for work & $53(2.5)$ & $124(3.1)$ \\
\hline
\end{tabular}

Note: $* P<0.0001,{ }^{\dagger} P<0.01$, and ${ }^{{ }^{\dagger}} P<0.05$ for mild vs moderate-to-severe OA pain. Abbreviation: $\mathrm{OA}$, osteoarthritis.

$(P<0.05$, data not shown). Additionally, higher proportions of the respondents with moderate-to-severe OA pain had OA for more than a decade (58.6\% vs $54.1 \%)$ and experienced daily OA pain compared with respondents with mild OA pain $(80.9 \%$ vs $48.8 \%)$.

Scores on all SF-36v2 domains were significantly lower (worse HRQoL) in those with moderate-to-severe OA pain compared with mild OA pain $(P<0.0001)$ (Figure 2A). Similarly, both the MCS (46.7 vs 52.3) and PCS (37.5 vs 46.5) scores on the SF-36v2 were significantly lower with moderate-to-severe OA pain vs mild OA pain (both $P<0.0001$ ) (Figure 2B). The health state utilities derived from the SF-6D and EQ-5D-5L also showed significantly poorer health status in the moderate-to-severe
OA pain respondents compared with mild OA (mean SF6D: 0.62 vs 0.72 ; mean EQ-5D-5L: 0.68 vs 0.80 ; both $P<0.0001$ ) (Figure 2C).

Among employed respondents, the percentage of lost work productivity was significantly higher in those with moderate-to-severe OA pain due to both absenteeism and presenteeism, with presenteeism resulting in greater work impairment (both $P<0.0001$ ) (Figure 3). Additionally, total work impairment (35.9\% vs $15.1 \%$ ) and overall activity impairment (49.8\% vs $23.6 \%$ ) were significantly higher in the moderate-to-severe OA pain cohort compared with mild OA pain (both $P<0.0001$ ) (Figure 3).

Respondents with moderate-to-severe OA pain took significantly more OTC acetaminophen $(26.5 \%$ vs 
Table 2 Clinical Characteristics

\begin{tabular}{|c|c|c|}
\hline \multirow[t]{2}{*}{ Variable } & \multicolumn{2}{|c|}{ Number of Patients (Weighted \%) } \\
\hline & Mild OA Pain $(n=2038)$ & Moderate-to-Severe OA Pain $(n=3798)$ \\
\hline \multicolumn{3}{|l|}{ Charlson Comorbidity Index } \\
\hline $0^{*}$ & $1545(76.1)$ & $2366(62.2)$ \\
\hline$I^{*}$ & $219(10.4)$ & $736(19.1)$ \\
\hline $2^{\dagger \dagger}$ & $185(9.2)$ & $428(11.4)$ \\
\hline $3^{*}$ & $54(2.6)$ & $|8|(5.0)$ \\
\hline$\geq 4$ & $35(1.8)$ & $87(2.3)$ \\
\hline \multicolumn{3}{|l|}{ BMI, $\mathrm{kg} / \mathrm{m}^{2}$} \\
\hline$<18.5$ (underweight) & $18(0.8)$ & $24(0.6)$ \\
\hline $18.5-<25$ (normal weight)* & $467(22.1)$ & $64 \mid(17.4)$ \\
\hline $25-<30$ (overweight)* & $678(34.5)$ & $946(26.0)$ \\
\hline$\geq 30$ (obese)* & $826(40.5)$ & $2067(53.0)$ \\
\hline Missing/unknown & $49(2.2)$ & $120(3.0)$ \\
\hline Alcohol use* & $1409(69.9)$ & $2262(60.0)$ \\
\hline \multicolumn{3}{|l|}{ Smoking status } \\
\hline Current smoker* & $215(10.2)$ & $685(17.5)$ \\
\hline Former smoker & $766(38.4)$ & $1385(36.6)$ \\
\hline Never smoked ${ }^{\dagger}$ & $1057(51.4)$ & $1728(46.0)$ \\
\hline Sleep disturbance ${ }^{a, *}$ & $16 \mid(7.8)$ & $627(16.4)$ \\
\hline Insomnia ${ }^{a, *}$ & $257(12.2)$ & $984(25.3)$ \\
\hline Depression $^{\mathrm{a}, *}$ & $504(23.6)$ & $1632(41.6)$ \\
\hline Generalized anxiety disorder ${ }^{\mathrm{a}, *}$ & $216(10.2)$ & $771(19.1)$ \\
\hline No exercise in the last month ( $\geq 20$ mins $)^{*}$ & $759(36.6)$ & $2032(53.5)$ \\
\hline
\end{tabular}

Notes: ${ }^{a}$ Patient-reported physician diagnosis. $* P<0.0001,{ }^{\dagger} P<0.01$, and ${ }^{{ }^{\dagger}} P<0.05$ for mild vs moderate-to-severe $O A$ pain.

Abbreviations: BMI, body mass index; OA, osteoarthritis.

$23.0 \%$ ) for their OA pain than those with mild OA pain $(P<0.01)$ (Figure 4). In contrast, use of ibuprofen was higher in mild OA pain respondents compared with moderate-to-severe $(24.9 \%$ vs $21.4 \%)$ as was use of acetylsalicylic acid (6.3\% vs $4.5 \%)$ (both $P<0.01)$. Additionally, use of an aid for OA, such as cold compresses, knee wraps, heat packs, patches, or braces was significantly higher for moderate-to-severe $\mathrm{OA}$ pain than mild $\mathrm{OA}$ pain $(8.9 \%$ vs $7.1 \%, P<0.05)$.

Nonsteroidal anti-inflammatory drugs (NSAIDs) and nontramadol opioids were the most prescribed pain medications in both cohorts (Table 4). However, a significantly higher proportion of moderate-to-severe OA pain respondents were prescribed OA pain medications overall $(41.0 \%$ vs $17.0 \%)$, including cyclooxygenase-2 (COX-2) inhibitors $(2.1 \%$ vs $1.2 \%)$, NSAIDs (18.3\% vs $7.9 \%)$, tramadol $(8.7 \%$ vs $3.3 \%)$, non-tramadol opioids ( $18.2 \%$ vs $5.3 \%)$, and steroids ( $2.5 \%$ vs $0.9 \%$ ) compared with mild OA pain (all $P<0.05$ ) (Table 4).
Moderate-to-severe OA pain respondents had higher adherence, ie, took more of their prescription pain medications $(75.9 \%)$ than those with mild OA pain $(64.1 \%)$ during the last month $(P<0.001)$. Moderate-to-severe OA respondents reported significantly lower overall satisfaction with their prescription pain medication compared with mild OA pain respondents $(4.9$ vs $5.3, P<0.0001)$ (Figure 5) and were significantly less satisfied with their prescription pain medication across classes (all $P<0.05$ ). On average, moderate-to-severe OA pain respondents scores were in the "somewhat satisfied" to "neither dissatisfied nor satisfied" range. For mild OA pain respondents, scores were higher and ranged between "somewhat satisfied" and "extremely satisfied".

Overall, higher proportions of those with moderate-tosevere OA reported HCRU visits in the past 6 months across all resource categories than respondents with mild OA pain including outpatient visits $(95.8 \%$ vs $94.3 \%$, 
Table 3 Osteoarthritis Characteristics

\begin{tabular}{|c|c|c|}
\hline \multirow[t]{2}{*}{ Variable } & \multicolumn{2}{|c|}{ Number of Patients (Weighted \%) } \\
\hline & Mild OA Pain $(n=2038)$ & Moderate-to-Severe OA Pain $(n=3798)$ \\
\hline \multicolumn{3}{|l|}{ OA type $\left(\geq 30 \%\right.$ of all respondents) ${ }^{a}$} \\
\hline Knee* & $1472(72.5)$ & $3040(79.5)$ \\
\hline Finger* & $871(4 I .9)$ & $1978(51.8)$ \\
\hline Hip* & $769(37.9)$ & $2055(53.5)$ \\
\hline Spine* & $694(34.0)$ & $1930(51.0)$ \\
\hline Hand* & $747(36.0)$ & $|84|(48.1)$ \\
\hline Shoulder* & $584(28.3)$ & $1665(43.6)$ \\
\hline Neck* & $505(24.6)$ & $|52|(39.5)$ \\
\hline \multicolumn{3}{|l|}{ Number of joints affected } \\
\hline I joint* & $415(20.8)$ & $395(10.5)$ \\
\hline I+ joints* & $1623(79.2)$ & $3403(89.5)$ \\
\hline Mean number of joints affected (SE)* & $3.4(0.05)$ & $4.8(0.05)$ \\
\hline \multicolumn{3}{|l|}{ Arthritis as a result of injury ${ }^{\dagger \dagger}$} \\
\hline Yes & $636(31.6)$ & $1377(36.1)$ \\
\hline \multicolumn{3}{|l|}{ Duration of OA, years } \\
\hline$<5^{\dagger}$ & $552(26.2)$ & $873(22.6)$ \\
\hline $6-10$ & $381(18.9)$ & $684(17.4)$ \\
\hline $11-15^{t \dagger}$ & $278(13.2)$ & $583(15.4)$ \\
\hline$\geq 16$ & $811(40.9)$ & $1603(43.2)$ \\
\hline Missing/unknown ${ }^{\dagger \dagger}$ & $16(0.8)$ & $55(1.5)$ \\
\hline \multicolumn{3}{|l|}{ Duration of OA pain } \\
\hline $0-3$ months $^{\dagger}$ & $12(0.6)$ & $4(0.12)$ \\
\hline$>3-6$ months & II (0.5) & $17(0.5)$ \\
\hline$>6-12$ months ${ }^{\dagger \dagger}$ & $27(\mathrm{I} .4)$ & $27(0.7)$ \\
\hline$>12-18$ months & II (0.5) & $14(0.4)$ \\
\hline$>18$ months -5 years & $225(10.9)$ & $376(9.7)$ \\
\hline$>5-10$ years & $257(12.2)$ & $497(12.6)$ \\
\hline$>10$ years* & $627(30.6)$ & 1402 (36.7) \\
\hline Missing/unknown ${ }^{\dagger}$ & $868(43.5)$ & $|46|(39.3)$ \\
\hline \multicolumn{3}{|l|}{ OA pain frequency } \\
\hline$<$ l time/month* & $89(4.0)$ & $18(0.5)$ \\
\hline 2-3 times/month* & $182(9.0)$ & $68(1.8)$ \\
\hline Once a week* & $94(4.7)$ & $4 \mid(1.2)$ \\
\hline 2-3 times/week* & $357(17.3)$ & $296(8.0)$ \\
\hline 4-6 times/week ${ }^{\dagger \dagger}$ & $231(11.3)$ & $354(9.3)$ \\
\hline Daily* & $853(41.8)$ & $2757(72.1)$ \\
\hline Missing/unknown* & $232(11.8)$ & $264(7.1)$ \\
\hline
\end{tabular}

Note: ${ }^{a}$ Not mutually exclusive. ${ }^{*} P<0.0001,{ }^{\dagger} P<0.01,{ }^{\dagger} P<0.01$, and ${ }^{{ }^{\dagger}} P<0.05$ for mild vs moderate to severe $O A$ pain.

Abbreviation: OA, osteoarthritis.

$P<0.05)$, emergency room visits $(18.9 \%$ vs $11.5 \%$, $P<0.0001)$, and hospitalizations $(10.8 \%$ vs $8.1 \%, P<0.01)$ (Figure 6).

\section{Discussion}

This study provides a holistic approach to the burden of OA pain from the respondents' perspective based on a nationally representative survey. Unique aspects of this study are that respondents who reported no OA pain in the last week were excluded from the analysis, and that the data set represents a population subsequent to the updated CDC guidelines for opioid use ${ }^{42}$ and therefore may be more aligned with current practice. In contrast, previous studies were conducted using data sets that antedate the 
A

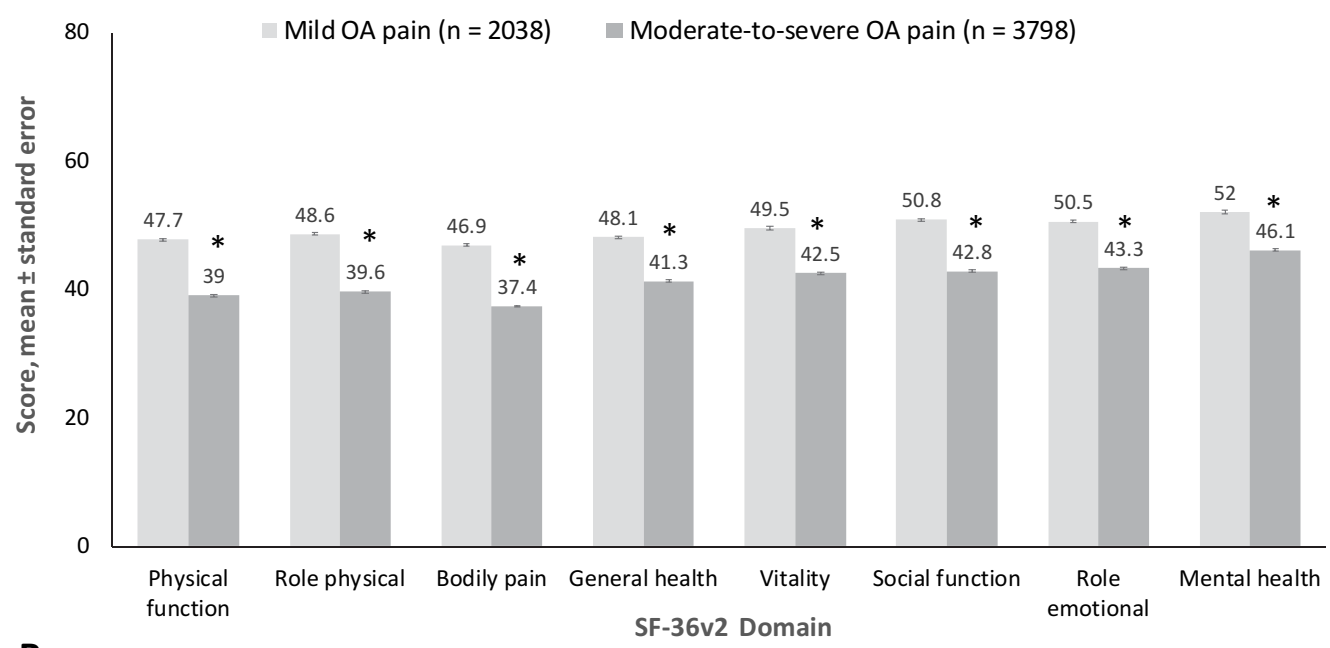

B

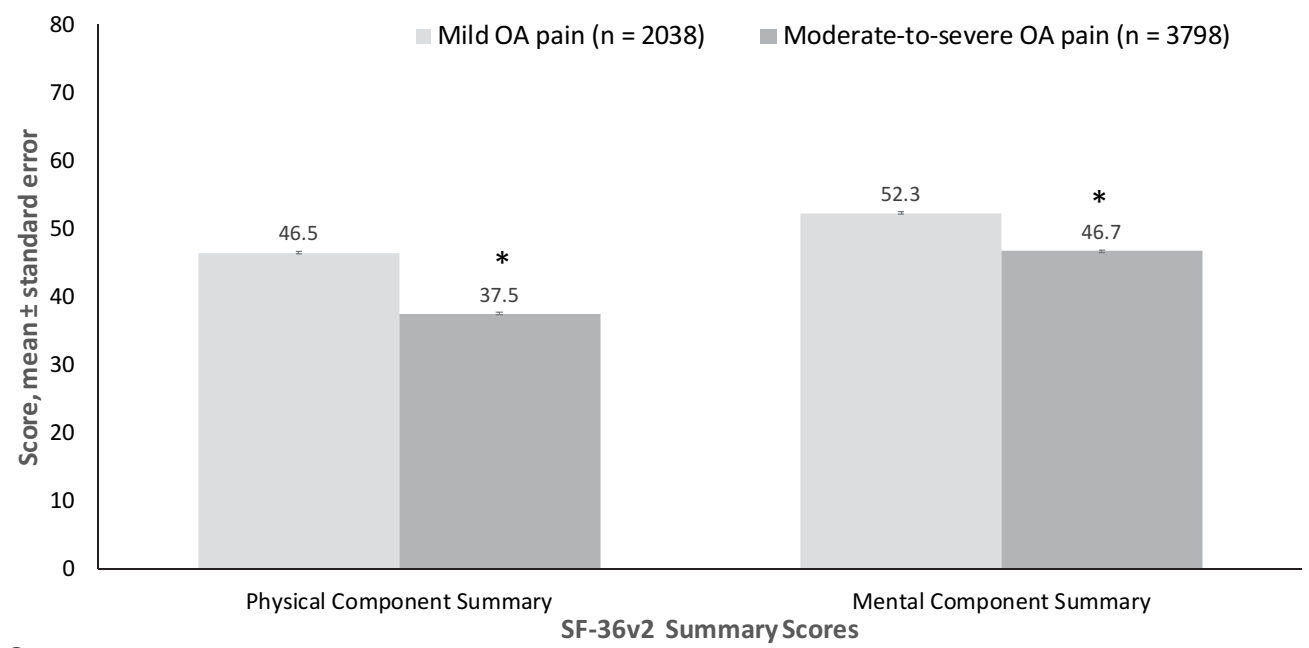

C

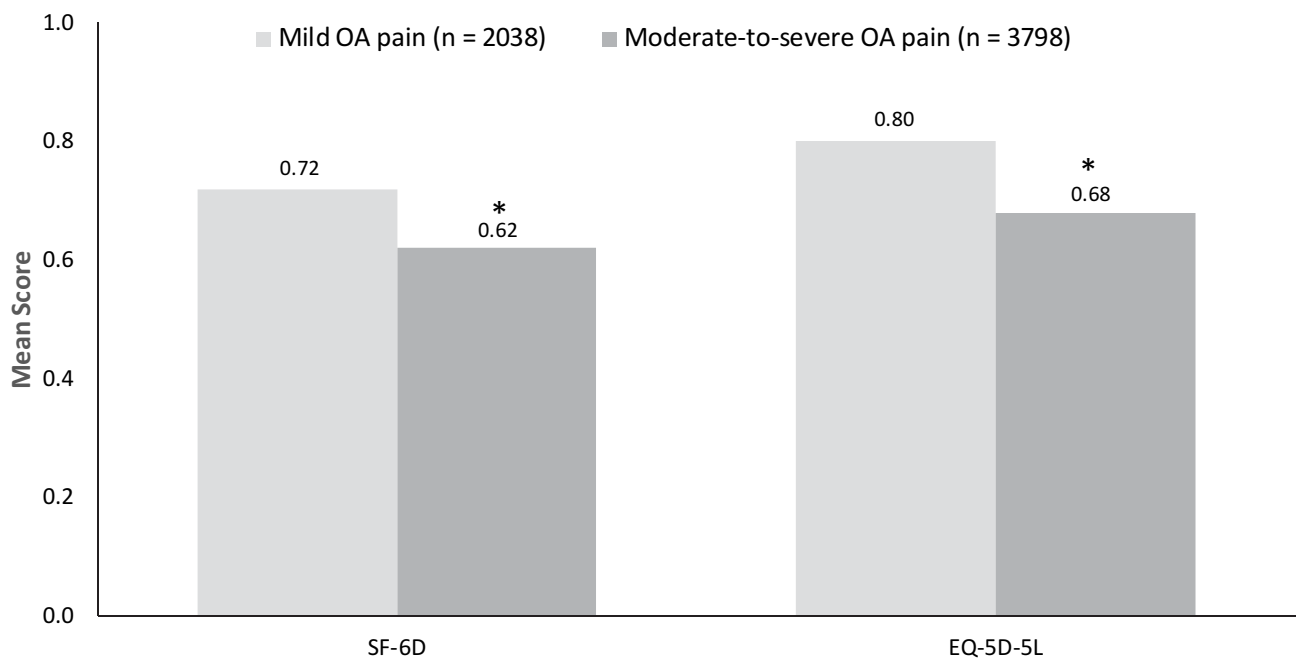

Figure 2 Health-related quality of life. (A) General health and well-being assessed on SF-36v2 domains. (B) Mental Component Summary (MCS) and Physical Component Summary (PCS) scores of the SF-36v2. (C) SF-6D and EQ-5D-5L health index scores.

Note: $* P<0.0001$ vs mild $O A$ pain.

Abbreviations: SF-6D, Short Form 6-dimension; SF-36v2, 36-item Short Form version 2. 


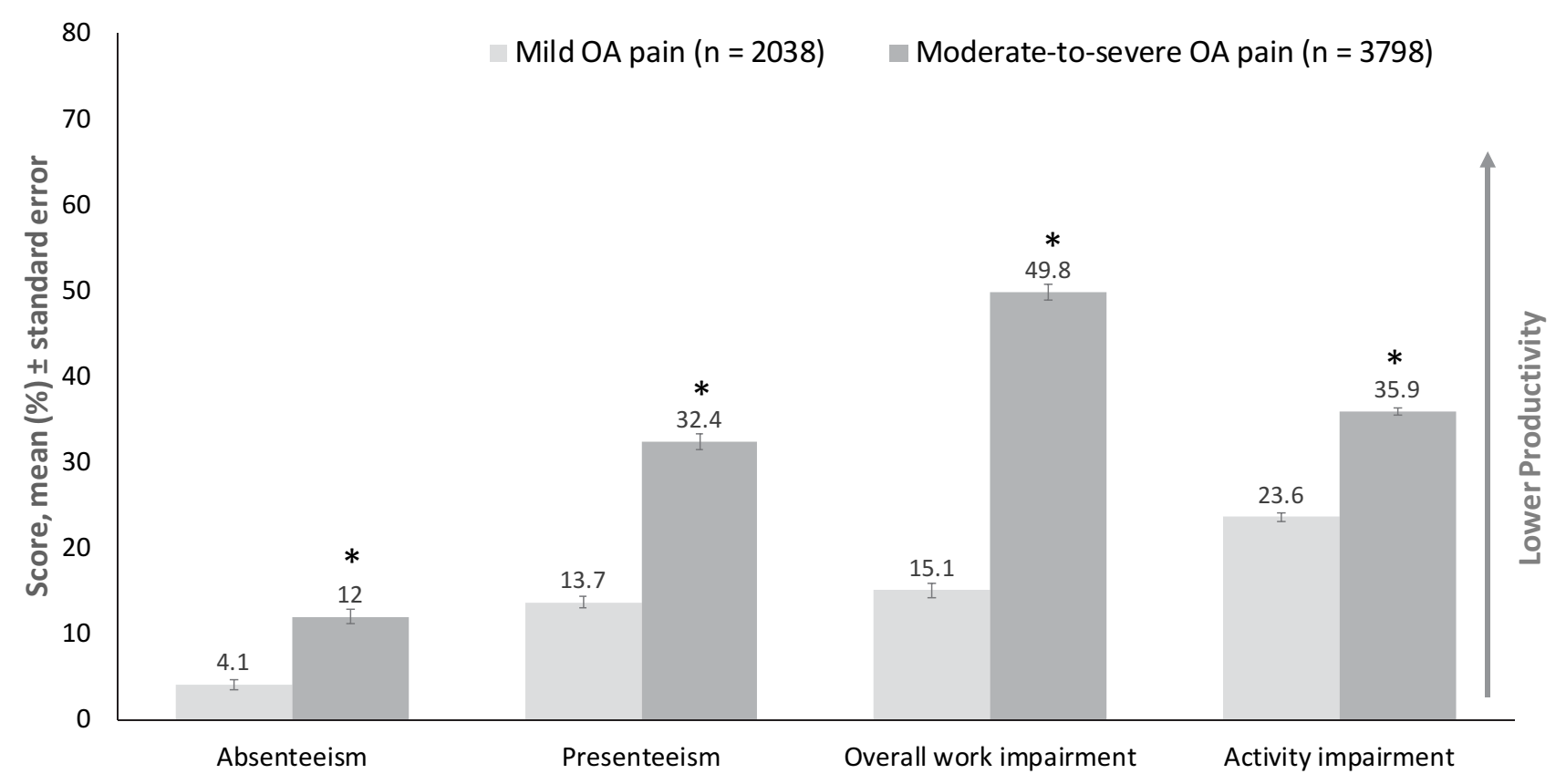

Figure 3 Impaired work and productivity assessed on the Work Productivity and Impairment Questionnaire for General Health (WPAI-GH)

Notes: ${ }^{a}$ Work productivity subscales evaluated only for responders who were employed; overall activity impairment evaluated among all responders. $* P<0.000 \mathrm{I}$ vs mild $O A$ pain.

Abbreviation: OA, osteoarthritis.

Mild OA pain $(n=2038) \quad$ Moderate-to-severe OA pain $(n=3798)$

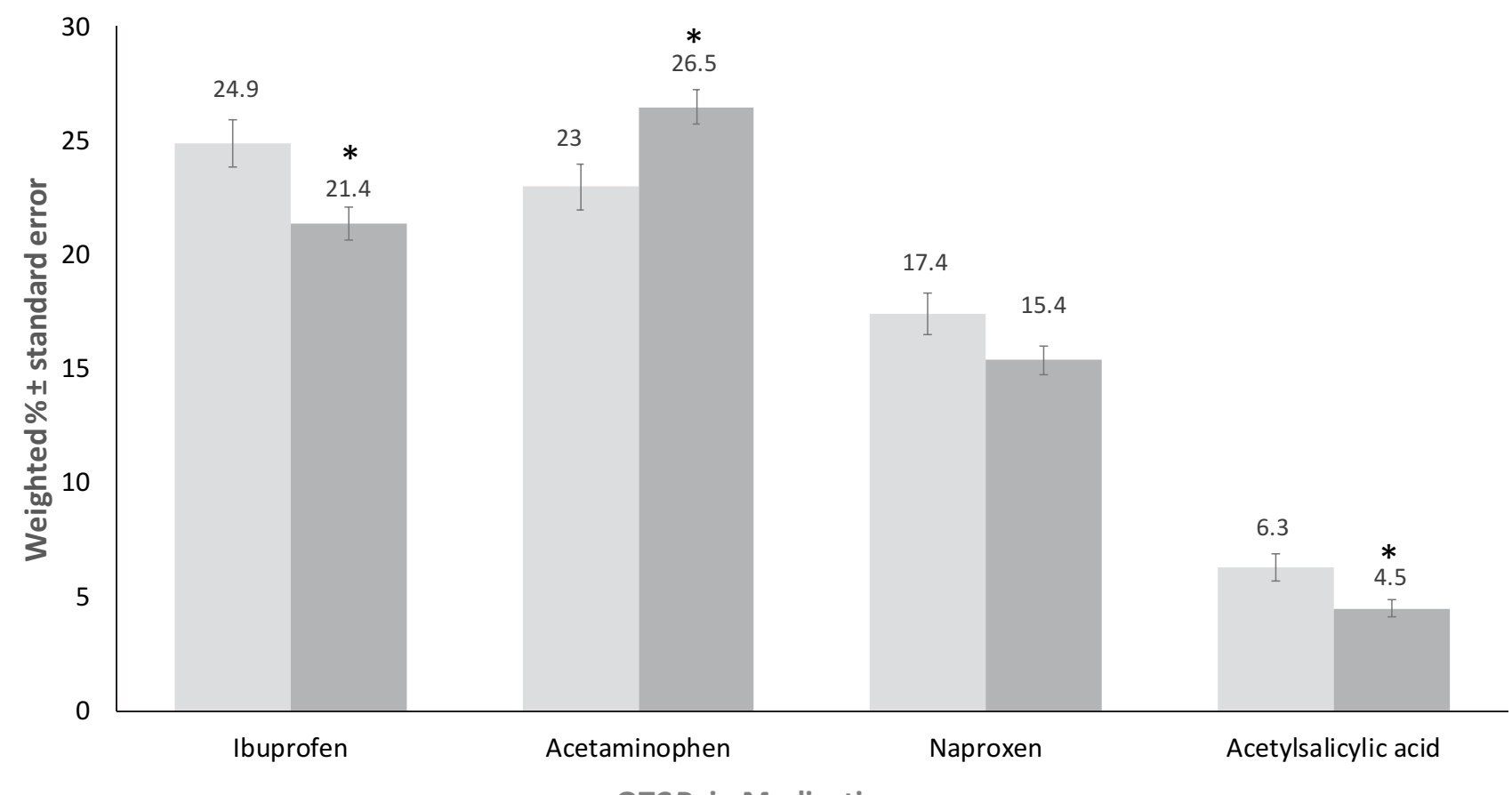

\section{OTC Pain Medication}

Figure 4 Current use of over-the-counter pain medications reported by OA patients ${ }^{\mathrm{a}}$.

Notes: ${ }^{a}$ Data are for OTC medications taken by $\geq 5 \%$ of either respondent group. ${ }^{*} P<0.0$ I, mild vs moderate to severe $O A$ pain.

Abbreviations: OA, osteoarthritis; OTC, over the counter. 
Table 4 Current Use of Select Prescription Pain Medications Reported by OA Patients

\begin{tabular}{|l|c|c|}
\hline \multirow{2}{*}{$\begin{array}{l}\text { Main } \\
\text { Medication }\end{array}$} & \multicolumn{2}{|c|}{ Number of Patients (Weighted \%) } \\
\cline { 2 - 3 } & $\begin{array}{c}\text { Mild OA Pain } \\
\text { (n = 2038) }\end{array}$ & $\begin{array}{c}\text { Moderate-to-Severe OA } \\
\text { Pain (n = 3798) }\end{array}$ \\
\hline Overall* & $364(17.0)$ & $1562(41.0)$ \\
COX-2 & \\
CNS & $26(1.2)$ & $86(2.1)$ \\
depressant & $4(0.2)$ & $18(0.4)$ \\
NSAID* & $170(7.9)$ & $697(18.3)$ \\
Tramado* & $68(3.3)$ & $335(8.7)$ \\
Non-tramadol & $112(5.3)$ & $687(18.2)$ \\
opioid* & & \\
Steroid* & $21(0.9)$ & $95(2.5)$ \\
Other $^{\mathrm{a}, *}$ & $53(2.2)$ & $247(6.4)$ \\
CCB/COX-2 $^{*}$ & $0(0)$ & $2(0.1)$ \\
TCA* $^{*}$ & $5(0.2)$ & $58(1.5)$ \\
SNRI & $119(2.9)$ \\
\hline
\end{tabular}

Notes: ${ }^{a}$ Other pain medications include dihydroergotamine mesylate, elagolix, ergotamine tartrate/caffeine, isometheptene/dichloralphenazone/acetaminophen, pentosan polysulfate sodium, transcranial magnetic stimulator. $* P<0.000$ I, ${ }^{\dagger} P<0.05$, and ${ }^{\ddagger} P<0.001$ for mild vs moderate-to-severe OA pain.

Abbreviations: $\mathrm{CCB}$, calcium channel blocker; CNS, central nervous system; COX, cyclooxygenase; NSAID, nonsteroidal anti-inflammatory drug; SNRI, serotonin-norepinephrine reuptake inhibitor; TCA, tricyclic antidepressant.

CDC guidelines, and either stratified their populations by disease severity rather than pain severity, ${ }^{20,21}$ or consisted of both symptomatic and asymptomatic patients, eg, the mild pain cohorts included OA patients with pain scores of zero (no pain). ${ }^{19,22-25}$ Among those studies, two did not confirm that the pain was specifically related to OA due to inherent limitations of the data source. ${ }^{19,22}$ Exclusion of patients with a zero pain score likely encompasses a more homogenous population with mild pain relative to the other studies. However, this cannot be confirmed since differentiation between no pain and mild OA pain patients in the mild cohorts was not reported.

Utilizing a robust sample size and ${ }^{23}$ multiple OA types, nearly one-third $(35 \%)$ of respondents reported their OA pain severity level as mild, while nearly two-thirds (65\%) reported moderate-to-severe OA pain. Collapsing the moderate and severe groups in the studies that reported 3 pain categories allowed us to compare results for a more severe population that is likely the target for several novel agents under investigation for OA pain ${ }^{43-47}$ and resulted in moderate-to-severe OA pain proportions that varied from $42 \%$ in Wei et $\mathrm{al}^{22}$ to $65 \%$ in the current study. In previous studies, no/mild OA pain ranged from $45 \%$ to $58 \%$ in patients that were not stratified by medication use. ${ }^{19,22-25}$ The lower proportions of mild and greater moderate-tosevere OA pain reported in this study are likely due to exclusion of respondents reporting no OA pain.

While moderate-to-severe OA pain respondents were significantly more likely to be female and of working age ( $<65$ years), they were also less likely to be employed and

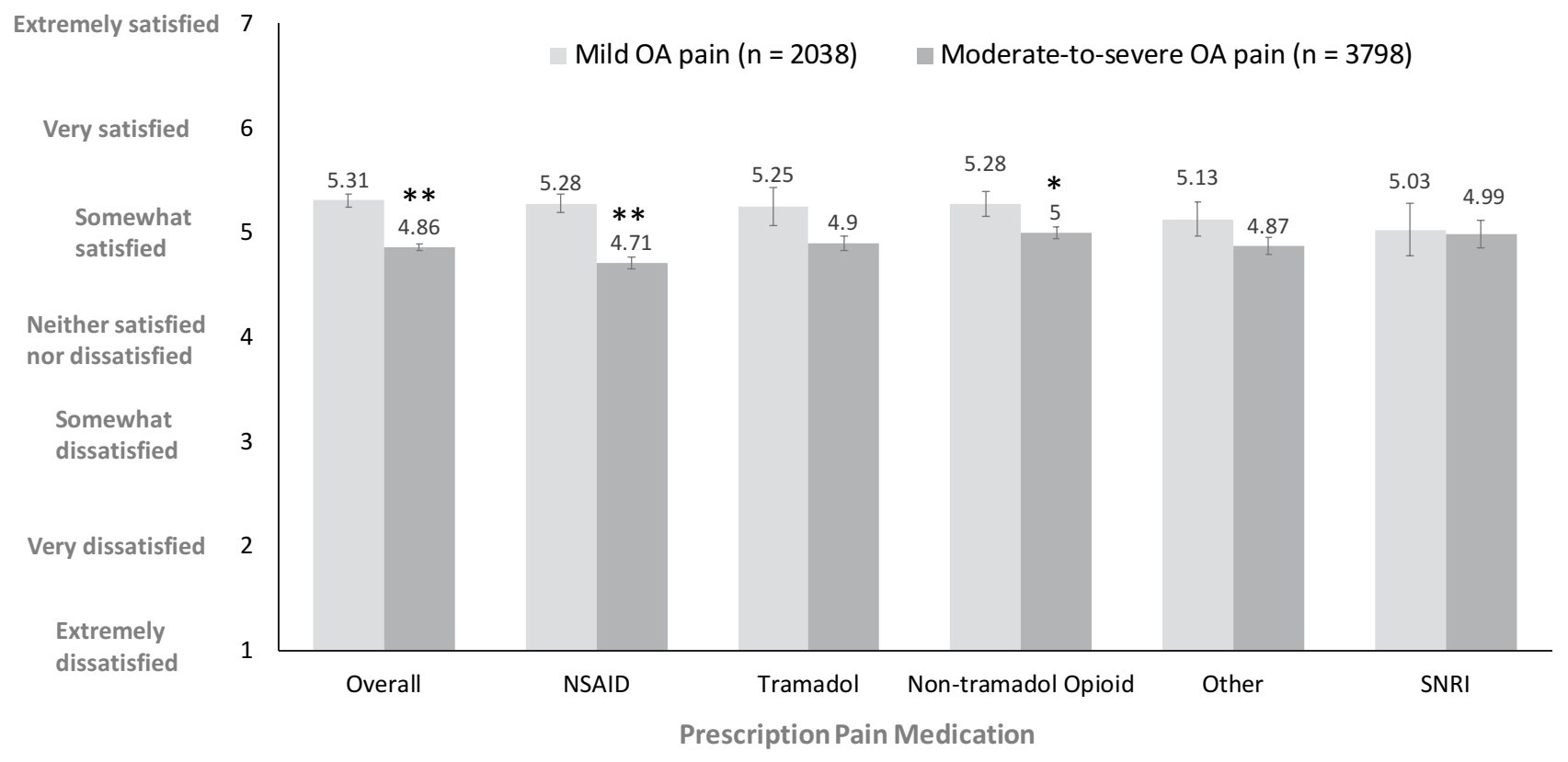

Figure 5 Satisfaction with currently prescribed OA medication ${ }^{\mathrm{a}}$.

Notes: ${ }^{a}$ All drugs that were statistically significant $(P<0.05) . * P<0.05, * * P<0.000$ I, mild vs moderate to severe OA pain.

Abbreviations: NSAID, nonsteroidal anti-inflammatory drug; OA, osteoarthritis; SNRI, serotonin-norepinephrine reuptake inhibitor. 


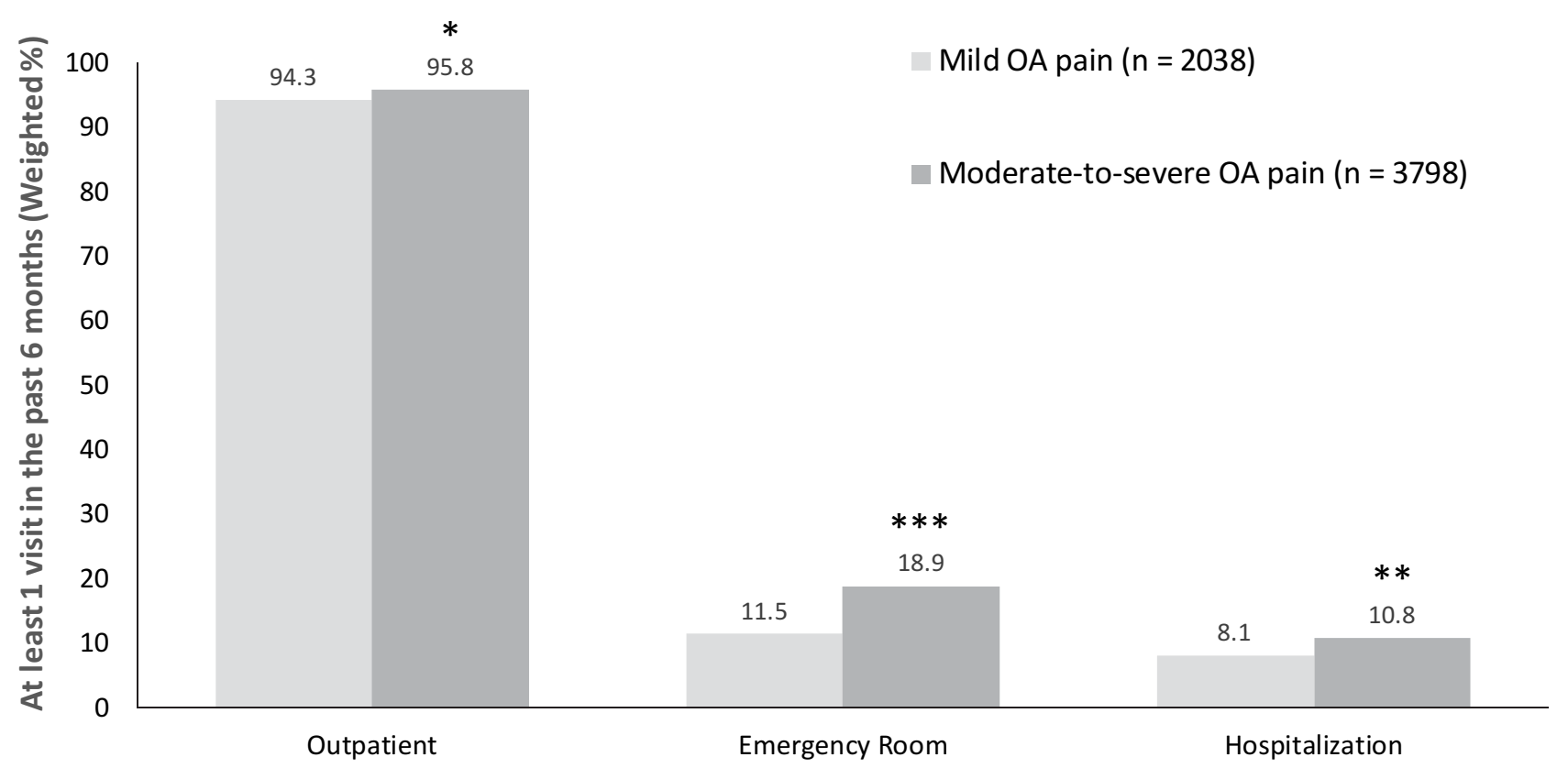

\section{Healthcare Resource Utilization}

Figure 6 Respondent-reported healthcare resource utilization in the past 6 months. Notes: $* P<0.05$, $* * P<0.01$, $* * * P<0.000$ I, mild vs moderate-to-severe OA pain. Abbreviation: OA, osteoarthritis.

have an income $\geq \$ 75,000$. These trends in employment and income were reported in both Zhao et $\mathrm{al}^{19}$ and Nalamachu et al. ${ }^{25}$ Similarly, the significantly greater prevalence of clinical comorbidities in moderate-to-severe respondents is consistent with those two studies; however, depression and insomnia were 2- to 4-fold greater, respectively, in the mild OA pain cohort in our study. Although these differences likely reflect the mild cohort definition, they may also be due to use of self-report in the current study relative to diagnostic coding in administrative claims or a physician-reported diagnosis in the medical chart at the time of the visit for OA.

Duration of OA was generally longer, and pain was more frequent, among those with moderate-to-severe OA pain compared with mild OA pain. Similarly, obesity (BMI $\geq 30)$ appeared to be more prevalent in the moderateto-severe pain respondents, consistent with 3 of the other pain severity studies. ${ }^{19,21,24,25}$

Moderate-to-severe OA pain respondents reported significantly poorer HRQoL compared with mild OA pain across all measures of HRQoL, with calculated health state utility values similar to those observed by Jackson et $\mathrm{al}^{23}$ in their non-opioid cohort. As observed for HRQoL, moderate-to-severe $\mathrm{OA}$ pain respondents reported a significantly greater impact on daily activities including work productivity compared to the mild OA cohort. Similar to our study, significantly greater impact on daily activities and work productivity was observed in moderate-to-severe patients reported by Jackson et al. ${ }^{23}$

This study also evaluated both OTC and prescription pain medication use specific to OA by pain severity level. Among the OTC medications, significantly greater use of acetaminophen was observed in moderate-to-severe OA respondents, and in contrast, significantly greater use of ibuprofen and acetylsalicylic acid was observed in mild OA respondents. These observations are generally consistent with the greater recommended use of acetaminophen and less recommended use of ibuprofen with increasing OA pain severity reported by Nalamachu et al. ${ }^{24}$ While the current study showed less usage of naproxen with increasing OA pain severity, this could potentially result from less recommended use as suggested in the study by Nalamachu et al. ${ }^{24}$

Overall, prescription pain medication was significantly greater in moderate-to-severe OA pain patients, compared with mild OA, driven by significantly greater use of most classes of pain medications including COX-2 inhibitors, NSAIDs, steroids, anti-depressants, tramadol, and nontramadol opioids. The overall low rates of prescription medication use among those with moderate-to-severe OA pain observed in our study compared to a recent study ${ }^{24}$ is 
likely attributable to differences in data sources; the NHWS captures both treated and non-treated respondents, and medication use is respondent-reported rather than physician-reported.

Interestingly, significantly greater adherence to pain medication was observed in moderate-to-severe OA pain respondents. This greater adherence may potentially be attributed to higher pain scores that provides a more constant reminder or awareness of their disease. Not unexpectedly, the higher rate of adherence observed in moderate-to-severe OA pain coincided with more respondents taking their prescription pain medications over a longer duration and at a higher frequency compared with mild OA pain. The greater duration of pain medication may also be reflective of disease progression where moderate-to-severe OA pain respondents experienced OA and OA-related pain for longer periods of time.

Among those taking prescription pain medication, treatment satisfaction was significantly lower in moderateto-severe OA respondents compared with the mild OA pain cohort, possibly because OA pain medications are symptomatic treatments, and have no impact on disease progression. Those with moderate-to-severe OA were characterized by more comorbid conditions and poorer HRQoL compared with mild OA and may have had more advanced disease. The relationship between satisfaction with treatment and OA progression warrants further investigation.

Significantly greater HCRU across all categories in the prior 6 months was observed in moderate-to-severe OA respondents compared with mild OA. While similar trends in resource utilization were generally observed in the other studies, ${ }^{19,22,25}$ heterogeneity in measurement and definitions precludes meaningful comparisons.

Strengths of this study include our ability to examine the impact of OA pain severity on a wide variety of outcomes using a robust and nationally representative sample size. However, as with any study, there are limitations, including the large sample, which could result in inferring statistical significance solely based on sample size. The study was based on patients' agreement to participate, and their perceptions may differ from those who refused to participate, introducing selection bias, and impacting generalizability. Additional selection bias may result from the fact that persons not seeking help from healthcare professionals for their symptomatic OA will not be captured in this analysis. The NHWS is broadly representative of the corresponding national adult population; however, as with other patient-reported surveys, it likely underrepresents people without access to or proficiency with internet use, as well as frail older adults, institutionalized patients, and those with severe comorbidities and disabilities. The survey relies on self-reported data where recall bias may be present, especially recall beyond 7 days. Further, clinician assessments like OA categorization and Kellgren-Lawrence grade were not captured. Finally, multiple joints may be affected, complicating the respondent's ability to classify their OA pain as mild, moderate, or severe.

Due to the cross-sectional nature of the study, any relationships should be considered associative rather than causal. Using general health rather than disease-specific measures may minimize the true impact of OA pain on patient outcomes. The survey did not capture information on prior medication use, which may be important when considering OA pain treatment patterns. From an analytic standpoint, univariate analysis identified differences between cohorts without adjustment for variables such as BMI, comorbid conditions, and age, that may have influenced outcomes. Despite these limitations, findings were consistent with other studies that assessed OA populations. Expanding this research to provide national estimates of the burden and to further apply these findings for the design of international studies of OA pain and its impact is warranted for a greater understanding of OA pain severity across populations.

\section{Conclusion}

This study confirms that moderate-to-severe OA pain has a significantly greater multidimensional impact compared with mild OA pain, including lower HRQoL, reduced work productivity, and a greater medication burden. In addition, despite greater adherence rates, moderate-to-severe OA pain respondents were less satisfied with their current pain medication. Higher OA pain severity was also associated with more HCRU, including outpatient visits, emergency room visits, and hospitalizations. Understanding this burden of OA pain with its clinical and economic implications in real-world settings may inform decision-making by stakeholders to ensure more effective pain management. Further studies that include prospective longitudinal assessment of these burdens associated with OA pain are warranted.

\section{Consent and Ethical Considerations}

All respondents provided informed consent.

\section{Acknowledgments}

The study was sponsored by Pfizer and Eli Lilly and Company. Pfizer and Eli Lilly and Company collaborated 
on study design and interpretation of results. Editorial support was provided by Alesia Sadosky of Apperture LLC and was funded by Pfizer and Eli Lilly and Company. The data that support the findings of this study are available on request from the corresponding author, ST.

\section{Author Contributions}

All authors contributed to data analysis, drafting or revising the article, gave final approval of the version to be published, agreed to the submitted journal, and agree to be accountable for all aspects of the work.

\section{Disclosure}

The findings of this manuscript have been presented at the ISPOR 2020 Virtual Annual Meeting; May 18-20, 2020 and at PAINWeek 2020 Virtual Meeting; September 11-13, 2020. The following authors are employees of Pfizer with stock and/or stock options: PS, ST, CB, DM, and BE. RR is an employee and stockholder of Eli Lilly and Company. AS was financially compensated for providing editorial support in the drafting of this manuscript. The authors report no other conflicts of interest in this work.

\section{References}

1. Gaskin DJ, Richard P. The economic costs of pain in the United States. J Pain. 2012;13(8):715-724. doi:10.1016/j.jpain.2012.03.009

2. Johannes CB, Le TK, Zhou X, Johnston JA, Dworkin RH. The prevalence of chronic pain in United States adults: results of an internet-based survey. J Pain. 2010;11(11):1230-1239. doi:10.1016/j. jpain.2010.07.002

3. Centers for Disease Control and Prevention. Prevalence of doctordiagnosed arthritis and arthritis-attributable activity limitation-United States, 2010-2012. MMWR Morb Mortal Wkly Rep. 2013;62 (44):869-873.

4. United States Bone and Joint Initiative. Osteoarthritis. The Burden of Musculoskeletal Diseases in the United States (BMUS). Rosemont, IL; 2018: Available from: https://www.boneandjointburden.org/fourthedition. Accessed January 14, 2020.

5. Neogi T. The epidemiology and impact of pain in osteoarthritis. Osteoarthritis Cartilage. 2013;21(9):1145-1153. doi:10.1016/j. joca.2013.03.018

6. Litwic A, Edwards MH, Dennison EM, Cooper C. Epidemiology and burden of osteoarthritis. Br Med Bull. 2013;105:185-199. doi:10.1093/ $\mathrm{bmb} / \mathrm{lds} 038$

7. Deshpande BR, Katz JN, Solomon DH, et al. Number of persons with symptomatic knee osteoarthritis in the US: impact of race and ethnicity, age, sex, and obesity. Arthritis Care Res (Hoboken). 2016;68 (12):1743-1750. doi:10.1002/acr.22897

8. Osteoarthritis Research Society International (OARSI). Osteoarthritis: a serious disease, submitted to the U.S. Food and Drug Administration; 2016. Available from: https://oarsi.org/sites/default/ files/docs/2016/oarsi_white_paper_oa_serious_disease_121416_1.pdf. Accessed January 14, 2021.
9. Centers for Disease Control and Prevention (CDC). Osteoarthritis (OA); 2020. Available from: https://www.cdc.gov/arthritis/basics/ osteoarthritis.htm. Accessed January 14, 2021.

10. Bitton R. The economic burden of osteoarthritis. Am J Manag Care. 2009;15(8 Suppl):S230-235.

11. Kotlarz H, Gunnarsson CL, Fang H, Rizzo JA. Osteoarthritis and absenteeism costs: evidence from US National Survey Data. J Occup Environ Med. 2010;52(3):263-268. doi:10.1097/JOM.0b013e3181cf00aa

12. Gore M, Tai KS, Sadosky A, Leslie D, Stacey BR. Clinical comorbidities, treatment patterns, and healthcare costs of patients with osteoarthritis in usual care: a database analysis. J Med Econ. 2011;14(4):497-507. doi:10.3111/13696998.2011.594347

13. Berger A, Bozic K, Stacey B, Edelsberg J, Sadosky A, Oster G. Patterns of pharmacotherapy and health care utilization and costs prior to total hip or total knee replacement in patients with osteoarthritis. Arthritis Rheum. 2011;63(8):2268-2275. doi:10.1002/ art.30417

14. DiBonaventura M, Gupta S, McDonald M, Sadosky A. Evaluating the health and economic impact of osteoarthritis pain in the workforce: results from the National Health and Wellness Survey. BMC Musculoskelet Disord. 2011;12:83. doi:10.1186/1471-2474-12-83

15. Gore M, Tai KS, Sadosky A, Leslie D, Stacey BR. Use and costs of prescription medications and alternative treatments in patients with osteoarthritis and chronic low back pain in community-based settings. Pain Pract. 2012;12(7):550-560. doi:10.1111/j.1533-2500.2012.00532.x

16. Murphy L, Helmick CG. The impact of osteoarthritis in the United States: a population-health perspective. Am J Nurs. 2012;112(3 Suppl 1):S13-19. doi:10.1097/01.NAJ.0000412646.80054.21

17. Xie F, Kovic B, Jin X, He X, Wang M, Silvestre C. Economic and humanistic burden of osteoarthritis: a systematic review of large sample studies. Pharmacoeconomics. 2016;34(11):1087-1100. doi:10.1007/s40273-016-0424-x

18. Wang SX, Ganguli AX, Bodhani A, Medema JK, Reichmann WM, Macaulay D. Healthcare resource utilization and costs by age and joint location among osteoarthritis patients in a privately insured population. J Med Econ. 2017;20(12):1299-1306. doi:10.1080/ 13696998.2017.1377717

19. Zhao X, Shah D, Gandhi K, et al. Clinical, humanistic, and economic burden of osteoarthritis among noninstitutionalized adults in the United States. Osteoarthritis Cartilage. 2019;27(11):1618-1626. doi:10.1016/j.joca.2019.07.002

20. Sadosky A, Bushmakin A, Cappelleri JC, Lionberger DR. Relationship between patient-reported disease severity in osteoarthritis and self-reported pain, function, and work productivity. Arthritis Res Ther. 2010;12:R162. doi:10.1186/ar3121

21. DiBonaventura M, Gupta S, McDonald M, Sadosky A, Pettit D, Silverman S. Impact of self-rated osteoarthritis severity in an employed population: cross-sectional analysis of data from the national health and wellness survey. Health Qual Life Outcomes. 2012;10:30. doi:10.1186/1477-7525-10-30

22. Wei W, Gandhi K, Blauer-Peterson C, Johnson J. Impact of pain severity and opioid use on health care resource utilization and costs among patients with knee and hip osteoarthritis. J Manag Care Spec Pharm. 2019;25(9):957-965. doi:10.18553/jmcp.2019.25.9.957

23. Jackson J, Iyer R, Mellor J, Wei W. The burden of pain associated with osteoarthritis in the hip or knee from the patient's perspective: a multinational cross-sectional study. $A d v$ Ther. 2020;37 (9):3985-3999. doi:10.1007/s12325-020-01445-4

24. Nalamachu SR, Robinson RL, Viktrup L, et al. Multimodal treatment patterns for osteoarthritis and their relationship to patient-reported pain severity: a cross-sectional survey in the United States. $J$ Pain Res. 2020;13:3415-3425. doi:10.2147/JPR.S285124

25. Nalamachu S, Robinson RL, Viktrup L, et al. Pain severity and healthcare resource utilization in patients with osteoarthritis in the United States. Postgrad Med. 2021;133(1):10-19. doi:10.1080/ 00325481.2020 .1841988 
26. Bellamy N. Western Ontario and McMaster Universities Osteoarthritis Index (WOMAC); 2021. Available from: http://www. auscan.org/womac/index.htm. Accessed January 14, 2021.

27. Melzack R. The McGill Pain Questionnaire: major properties and scoring methods. Pain. 1975;1(3):277-299. doi:10.1016/03043959(75)90044-5

28. Melzack R. The short-form McGill Pain Questionnaire. Pain. 1987;30:191-197. doi:10.1016/0304-3959(87)91074-8

29. Ware JE, Kosinski M, Turner-Bowker D, Sundaram M, Gandek B, Maruish ME. User's Manual for the SF-12v2 Health Survey Second Edition. Lincoln, RI: QualityMetric Incorporated; 2009.

30. Hawker GA, Mian S, Kendzerska T, French M. Measures of adult pain: Visual Analog Scale for Pain (VAS Pain), Numeric Rating Scale for Pain (NRS Pain), McGill Pain Questionnaire (MPQ), Short-Form McGill Pain Questionnaire (SF-MPQ), Chronic Pain Grade Scale (CPGS), Short Form-36 Bodily Pain Scale (SF-36 BPS), and measure of Intermittent and Constant Osteoarthritis Pain (ICOAP). Arthritis Care Res (Hoboken). 2011;63(Suppl 11):S240252.

31. Kantar Health. National Health and Wellness Survey. Patient-reported healthcare insights; 2019. Available from: https:/www.kantarhealth. com/docs/datasheets/kh-national-health-and-wellness-survey.pdf. Accessed January 28, 2021.

32. Boonstra AM, Schiphorst Preuper HR, Balk GA, Stewart RE. Cut-off points for mild, moderate, and severe pain on the visual analogue scale for pain in patients with chronic musculoskeletal pain. Pain. 2014;155(12):2545-2550. doi:10.1016/j.pain.2014.09.014

33. Charlson ME, Pompei P, Ales KL, MacKenzie CR. A new method of classifying prognostic comorbidity in longitudinal studies: development and validation. J Chronic Dis. 1987;40(5):373-383. doi:10.1016/0021-9681(87)90171-8

34. Maruish M, Maruish M, Kosinski M, et al. User's Manual for the SF36v2 Health Survey. 3rd Ed. Lincoln, RI: QualityMetric Incorporated; 2011.

35. Brazier J, Roberts J, Deverill M. The estimation of a preference-based measure of health from the SF-36. J Health Econ. 2002;21(2):271-292. doi:10.1016/S0167-6296(01)00130-8

36. The EuroQol Group. EQ-5D-5L user guide; 2021. Available from: https://euroqol.org/publications/user-guides/. Accessed June 11, 2017.

37. Conner-Spady BL, Marshall DA, Bohm E, et al. Reliability and validity of the EQ-5D-5L compared to the EQ-5D-3L in patients with osteoarthritis referred for hip and knee replacement. Qual Life Res. 2015;24(7):1775-1784. doi:10.1007/s11136-014-0910-6
38. Bilbao A, Garcia-Perez L, Arenaza JC, et al. Psychometric properties of the EQ-5D-5L in patients with hip or knee osteoarthritis: reliability, validity and responsiveness. Qual Life Res. 2018;27 (11):2897-2908. doi:10.1007/s11136-018-1929-x

39. Reilly MC, Zbrozek AS, Dukes EM. The validity and reproducibility of a work productivity and activity impairment instrument. Pharmacoeconomics. 1993;4:353-365. doi:10.2165/00019053199304050-00006

40. Reilly MC. Work productivity and activity impairment questionnaire: specific health problem V2.0 (WPAI:SHP); 2010. Available from: http://www.reillyassociates.net/WPAI_SHP.html. Accessed January 14, 2021.

41. Thompson K, Kulkarni J, Sergejew AA. Reliability and validity of a new Medication Adherence Rating Scale (MARS) for the psychoses. Schizophr Res. 2000;42(3):241-247. doi:10.1016/S09209964(99)00130-9

42. Dowell D, Haegerich TM, Chou R. CDC guideline for prescribing opioids for chronic pain-United States, 2016. JAMA. 2016;315 (15):1624-1645. doi:10.1001/jama.2016.1464

43. Dakin P, DiMartino SJ, Gao H, et al. The efficacy, tolerability, and joint safety of fasinumab in osteoarthritis pain: a phase IIb/III double-blind, placebo-controlled, randomized clinical trial. Arthritis Rheumatol. 2019;71(11):1824-1834. doi:10.1002/art.41012

44. Berenbaum F, Blanco FJ, Guermazi A, et al. Subcutaneous tanezumab for osteoarthritis of the hip or knee: efficacy and safety results from a 24-week randomised phase III study with a 24-week follow-up period. Ann Rheum Dis. 2020;79(6):800-810. doi:10.1136/annrheumdis-2019-216296

45. Schnitzer TJ, Easton R, Pang S, et al. Effect of tanezumab on joint pain, physical function, and patient global assessment of osteoarthritis among patients with osteoarthritis of the hip or knee: a randomized clinical trial. JAMA. 2019;322(1):37-48. doi:10.1001/ jama.2019.8044

46. Krupka E, Jiang GL, Jan C. Efficacy and safety of intra-articular injection of tropomyosin receptor kinase $\mathrm{A}$ inhibitor in painful knee osteoarthritis: a randomized, double-blind and placebo-controlled study. Osteoarthritis Cartilage. 2019;27(11):1599-1607. doi:10.1016/j.joca.2019.05.028

47. Stevens RM, Ervin J, Nezzer J, et al. Randomized, double-blind, placebo-controlled trial of intraarticular trans-capsaicin for pain associated with osteoarthritis of the knee. Arthritis Rheumatol. 2019;71 (9):1524-1533. doi:10.1002/art.40894
Journal of Pain Research

\section{Publish your work in this journal}

The Journal of Pain Research is an international, peer reviewed, open access, online journal that welcomes laboratory and clinical findings in the fields of pain research and the prevention and management of pain. Original research, reviews, symposium reports, hypothesis formation and commentaries are all considered for publication. The manuscript management system is completely online and includes a very quick and fair peer-review system, which is all easy to use. Visit http:// www.dovepress.com/testimonials.php to read real quotes from published authors. 